\title{
Stephen Hancocks celebrates 15 years as
} Editor-in-Chief

On 16 January 2020 friends and colleagues of the BDJ's Editor-inChief Stephen Hancocks gathered in Covent Garden to celebrate Stephen being the longest-serving $B D J$ editor since the journal was launched in the late 1800 s.

Stephen, who is interviewed in this issue of the $B D J$, was presented with a bound copy of all of his editorials from the past 15 years.

Commenting on the occasion, Stephen said: 'These past 15 years have flown by but so much has changed within the journal and now its accompanying portfolio of titles. However, none of this would have been possible without a brilliant, brilliant team.'

The $B D J$ editorial team also bid farewell to Dr Ruth Doherty, Senior Managing Editor, who has worked for the BDJ since 2012. Ruth has now returned to her native Ireland and will be greatly missed by colleagues.

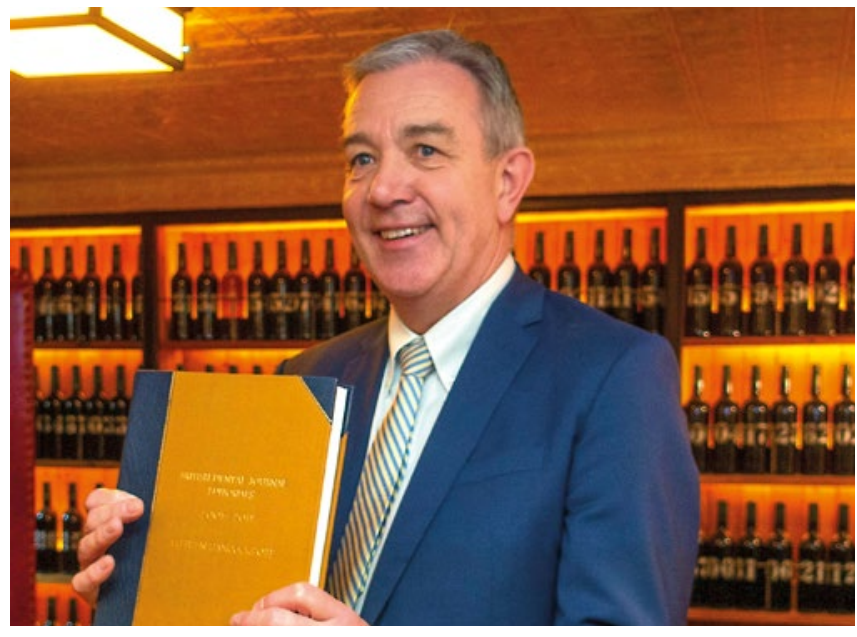

Stephen Hancocks OBE celebrating 15 years as Editor-in-Chief of the BDJ

\section{Increased demand for aid within the dental profession}

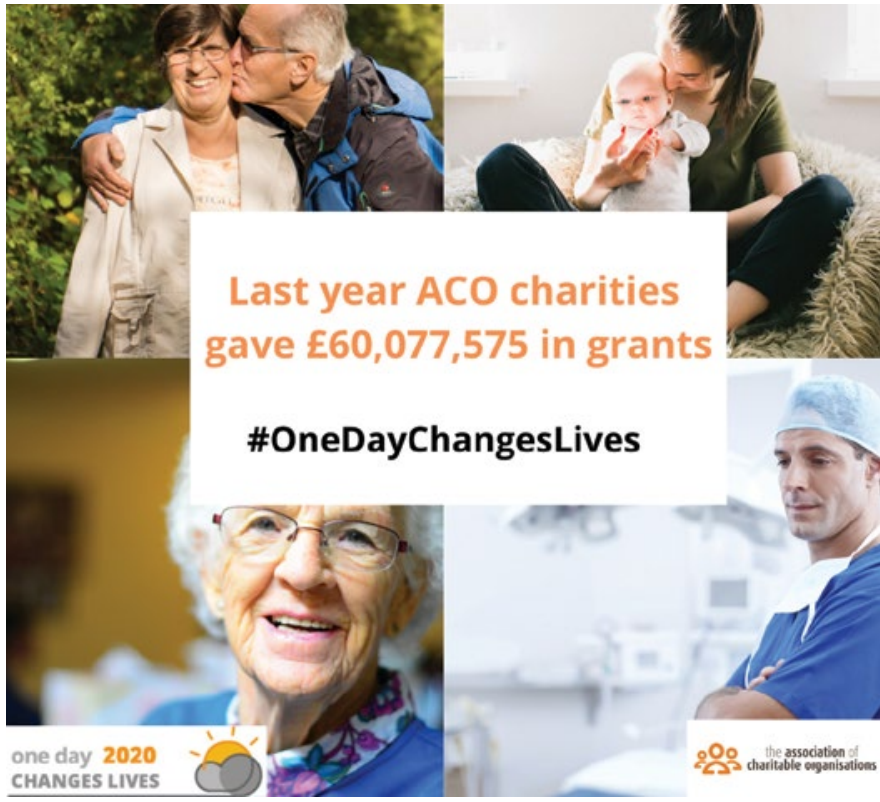

With January intensifying the difficulties people face financially and emotionally, new research has revealed nearly half a million people turned to charities for help in just one year.

National data from the Association of Charitable Organisations (ACO) shows the number of people seeking help from charities and benevolent funds because they have nowhere else to turn following an unexpected change in circumstances has risen over the last four years.

The BDA Benevolent Fund, that has supported over 9,000 dental students, dentists and their families since it was established in 1883 , has helped with support including funds for daily living costs such as food, rent and utility bills. Assistance was also given towards students facing undue hardship as well as to those returning to dentistry following a break or illness with funds towards indemnity payments, annual registration fees and continuing professional development.
The ACO represents more than 120 charities, including the BDA Benevolent Fund, that provide financial support in the form of grants, which help thousands of people across the UK. A recent survey of members showed that more than 100,000 people applied for financial help in the last financial year. When extrapolated across its entire membership base, it is estimated ACO member charities will have supported at least 400,000 people in need. In 2015, the charities

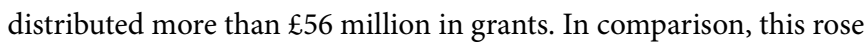
to more than $£ 60$ million last year - $£ 216$ million when applied to its entire membership base.

The BDA Benevolent Fund has also found that requests for help have increased year on year. The charity received more applications in 2019 than in any year and a 10\% increase on the year before.

Dr Ros Keeton, Chairman of the BDA Benevolent Fund, said: 'The impact of the relatively small but incredibly caring and generous group that makes up the dental profession cannot be overstated. It's down to the profession to care for their own. Working together under the auspices of the BDA Benevolent Fund, lives can change for the better on an ongoing basis'.

Following strategic discussions and noticing the trends in the types of calls for assistance, the BDA Benevolent Fund is developing other ways to assist their applicants and the profession as a whole. Starting from Monday 20 January, applicants, should they wish, can be referred to receive legal, financial and emotional support and counselling sessions as well as the financial aid traditionally given out.

Noticing that people often ask for help due to issues with cash flow and debts, the charity will also be launching a series of free of charge webinars in the spring to ensure dental students, dentists and their families can get accessible and helpful guidance to assist them to maximise their resources, both now and for the future.

If you are an individual in need of support, please visit https://www. bdabenevolentfund.org.uk/request-help/. 